\title{
Peertechz
}

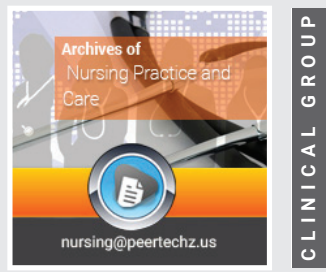

\section{Attitudes of undergraduate} nursing students towards violence against women and their occupational roles in addressing violence

\author{
Gul Pinar ${ }^{1 *}$ and Ebru Pınar ${ }^{2}$
}

'Department of Nursing, Faculty of Heath Science, Ankara Yıldırım Beyazıt University, Turkey ${ }^{2}$ Department of Psychology, Atlanta Georgia State University, USA

Received: 16 December, 2021

Accepted: 06 January, 2022

Published: 07 January, 2022

*Corresponding author: Gul Pinar, Department of Nursing, Faculty of Heath Science, Ankara Yıldırım Beyazıt University, Turkey, Tel: +9 (0) 312324155 / 4556; E-mail: gpinar_1@hotmail.com

Keywords: Violence against women; Nursing student; Attitude

Copyright License: (c) 2022 Pinar G, et al. This is an open-access article distributed under the terms of the Creative Commons Attribution License, which permits unrestricted use, distribution, and reproduction in any medium, provided the original author and source are credited.

https://www.peertechzpublications.com

Check for updates

\section{Abstract}

Aim: This study was performed in order to determine the attitudes of nursing students towards violence against women (VAW) and their occupational roles in addressing violence.

Method: This descriptive study was conducted on nursing students ( $\mathrm{n=108)}$ at a State University in Ankara, Turkey. 1) Personal information form, 2) The attitudes towards VAW, and 3) The attitudes towards occupational role VAW scale were used for data collection. In data evaluation, frequencies, percentage, mean, standard deviation, t-test for independent samples and one-way analysis of variance tests were used.

Results: The mean age of the students was $20.13 \pm 1.17$ ( $\min : 18$, max: 26 ). It was determined that the mean of the VAW attitudes of the students of nursing is 74.15 \pm 12.01 . The attitudes of the students were found far from the modern view. Female students were closer to the conservative view ( $<<0.05$ ). The mean of attitude of the students related to the occupational role is $70.24 \pm 9.30$. The students were did not have a tendency for supportive occupation roles towards VAW. Students' age, parents' education and profession, income level, and residence were not found to influence the attitude towards VAW and their occupational roles in addressing violence $(p>0.05)$

Conclusion: As a result of this study, non-contemporary attitudes and disapprove occupational roles towards VAW are still a major problem among nursing students. The nursing students should be educated in terms of awareness and knowledge towards VAW.

\section{Introduction}

Violence Against Women (VAW) is a violation of fundamental human rights and freedom and is a public health problem that arises as a result of historically unequal power relations between men and women to achieve legal, social, political, and economic equality. VAW is based on gender stereotypes and it is perpetrated against women in most cases as compared to those against men [1-3]. Recent studies have shown that women who experience violence are at a higher risk of all social, financial, mental, sexual and physical health issues such as death, serious injury, sexually transmitted disease, acute or chronic pain, headache, drug-alcohol abuse, fractures, menstrual irregularity, sexual abuse, drug-alcohol abuse, criminal activity, rape, perinatal complications, unwanted pregnancy, miscarriage, low birth weight, sexually transmitted disease, conversion disorders, social isolation, insomnia, post-traumatic stress syndrome, somatization, fear, anxiety, depression, bullying, attempt suicide, maltreatment, acute and chronic poor health outcomes that require medical attention [4-9].

A population-based study across 161 countries (2018) reported that worldwide, nearly 1 in 3 women (around 8000 million) have been victim to violence by an intimate partner or non-partner in their lifetime ( $15 \%$ west regions $-71 \%$ east regions). According to this report, it has been estimated that VAW causes a greater health problem than traffic accidents and other diseases [3]. In addition, United Nations (UN) stated 
that the cost of VAW is 1.16 billion dollars in Canada, 5.8 billion dollars in the USA, and 11.38 billion dollars in Australia [2]. Currently, the women's movements have an important role in enhancing attention to the severity of the problems of VAW and to ensuring elimination its incidence by building the evidence and knowledge base for primary prevention, especially with reference to groups of women particularly of vulnerable to violence such as with disabilities, refugee or migrant women, elderly or female children women, women living rural area, women in detention, and destitute women or orphan status. Many countries have adopted specific laws to cope with VAW and they started to physical, social, physiological, and legal support services for women who experience violence. Currently, experiences have indicated that it is easier to change the law than to change practices and beliefs. Despite all progress, VAW remains an endemic problem in the world. Therefore, specific efforts are required to address for minimizing of VAW by the government and non-government sectors at multiple levels of a community [10-13].

Health institutions are an important sector in the screening and management of women who are victims of violence. A policy guideline for health providers regarding appropriate care and an elaborated curriculum towards survivors of violence was developed by the WHO [3]. All health providers, especially nurses, are often the first contact for violence victims and they have opportunities to prevent violence by informing and screening. Women who are exposed to violence can comfortably share their problems with the nurses. Nurses are increasingly likely to encounter victims of violence and many forms of evidence. For this reason, nurses' attitudes and behaviors towards VAW may have an intense impact on the protection of victims. It is also essential to raise the awareness of nursing students about VAW and to eliminate their deficiencies before they start their practice. Briefly, nurses play an important role in the early identification, prevention, and management of VAW for victims $[5,7,14,15]$. Unfortunately, previous studies have demonstrated that nurses and nursing students did not have adequate knowledge and awareness of the determining features of VAW [11,16-18].

\section{Purpose}

The purpose of this study was to assess the attitudes of nursing students towards VAW and their professional roles in addressing violence.

\section{Materials and methods}

\section{Study type, population, sample, and setting}

This descriptive study was conducted in 2014. The population was composed of the students recruited to the Nursing Department of State University in Ankara, Turkey $(\mathrm{N}=112)$. The 108 students who volunteered were included in the final sample. The students in the third year were chosen as the sample since they have just taken the Women's Health course.

\section{Eligibility criteria and ethical consideration}

Eligibility criteria for nursing students were: (a) can read and write in Turkish, (b) agree to participate in the research, and (c) the students in the third year. Students who fill in the questions incompletely will be excluded from the study. Permission was obtained from the Board of University to conduct the study. Rules specified in The Helsinki Declaration were observed in the data collection phase.

\section{Data collection}

In the collection of data: 1) Questionnaire Form (QF), Attitude Towards Violence Scale (AVS), Attitude Regarding Occupational Roles in Violence Scale (AORVS) and were used. The pre-test of the research was carried out on 10 students and it was determined that the questions in the data collection tools were understandable. All forms were distributed to the students by the researchers in the classroom. The filled forms were collected as participants completed answering them. It took approximately 20 minutes to fill out the forms.

QF: This form was prepared by the researchers after the literature review. There are a total of 9 questions concerning students' age, gender, mother's education, father's education, mother's and father's profession, place of residence, income status, and their views towards VAW in the nursing curriculum.

AVS: This scale was used to evaluate the attitudes of nursing students towards VAW, which was developed by Gombul [19] in Turkey. This Likert type scale consists of 19 items on fivepoints; 1 - strongly disagree, 2-disagree, 3-neither agree nor disagree, 4-agree, and 5- strongly agree. This scale has four subscales: 1) economic violence (mean:21, min:7, max:35), 2) emotional, psychological, and sexual violence (mean:18, min:6, max.30), 3) legitimizing myths (mean:9, min:3, max.15), and 4) explanatory myths (mean:6, min:2, max:10). The mean score of the scale is 57 (min: 19, max: 95). High scores from the scales reflect an increase in traditional attitudes towards violence, while the low scores reflect an increased contemporary perspective. Cronbach's alpha was 0.75 .

AORVS: This scale was used to examine the attitudes of students regarding occupational roles in violence, which was developed by Gombul [19] in Turkey. The scale consists of 15 items and each item is scored between 1 and 5 on a five-point Likert scale. (min:15, max:75). The scale has four subscales to evaluate 1) the supportive initiatives of the health personnel (mean: 18, min: 6, max:30), 2) to continue the marriage under all conditions (mean:12, min:4, max:20), 3) to end the marriage union (mean: 6, min: 2, max:10) and 4) to evaluate the negative view of the role of the health personnel (mean:9, min:3, max:15). The mean score of the scale is 45 . High scores from the scales reflect an increase in traditional attitudes towards violence, while the low scores reflect an increased contemporary perspective. Cronbach's alpha was 0.72 .

\section{Data analysis}

The analyses were undertaken in the Statistical Package for Social Sciences 21.0 (SPSS) package software. Descriptive statistics were evaluated using the number, percentage, mean and standard deviation, with a $95 \%$ confidence interval (95\% $\mathrm{CI})$. One-way ANOVA test was utilized for the comparison of the

Citation: Pinar G, Pınar E (2022) Attitudes of undergraduate nursing students towards violence against women and their occupational roles in addressing violence. Arch Nurs Pract Care 8(1): 001-006. DOI: https://dx.doi.org/10.17352/anpc.000058 
scale scores as per the variables under more than two categories. The independent samples t-test was used for the scale scores having shown a normal dispersion through the comparison of the scores as per the variables under two categories. TukeyHDS test was used to determine which means amongst a set of means differ from the others. The significance level was $\mathrm{p}<0.05$.

\section{Results}

The mean age of the students was $20.13 \pm 1.17$ (min:18, max:26). $79.6 \%$ of the students were female, $20.4 \%$ of the students were male, and $78.7 \%$ of the students were at $20-24$ years. $62.9 \%$ of their mother's education level was a primary school and $44.0 \%$ of their father's education level was a primary school. The mothers of the majority of the students $(73.2 \%)$ were housewives, and the fathers of $73.2 \%$ were employed. The place where $77.7 \%$ of the students lived for a long time was in the urban area, and $67.9 \%$ of the students had a medium income (Table 1$)$. In addition, the majority of students (85.4\%) stated that VAW should be included in the nursing curriculum.

The mean score for AVS was $74.15 \pm 12.01(\min =20, \max =95)$. When the distribution of the AVS subscale scores was analyzed, it was determined that the mean economic violence score was $26.15 \pm 5.31$, the mean emotional, psychological and sexual violence score was $18.24 \pm 4.32$, the mean score for legitimating myths was $12.16 \pm 3.01$, and the mean for explanatory myths was $10.15 \pm 2.21$. The high mean scores of the scale indicated that the students agreed with more traditional attitudes towards VAW (Table 2).

The students' mean AORVS score was 65.24 \pm 9.30 (min= 20, $\max =90$ ). It was determined that this ratio was higher than the mean score of the original scale (mean $=45$ ). When the distribution of AORVS subscale mean scores is examined; the mean score for supportive nursing interventions was $25.11 \pm 5.36$, the mean score for maintaining the marriage under all conditions was $13.10 \pm 3.39$, the mean score for ending the marriage was $10.12 \pm 1.11$, and the mean score for the negative view of the nurse's role regarding violence was $11.23 \pm 2.84$. According to this result, nursing students did not seem much a positive attitude towards their occupational roles on VAW, especially a supportive force in the resolution of violence (Table 3).

There was a statistically significant relationship between the mean scores of AVS of the students and gender $(\mathrm{p}<0.05)$. While the mean AVS score was $57.12 \pm 11.00$ for male students, it was $75.23 \pm 8.13$ for female students. Accordingly, it can be said that male students have a more modern view towards VAW. When the students' mean AVS scores were compared according to their father's profession, it was found that there was a statistically significant difference between the groups. It was found that the group whose father was retired $(65.10 \pm 12.83)$ had a more contemporary attitude towards violence than those who were employed $(71.11 \pm 8.10)$. However, this difference was not statistically significant $(\mathrm{p}>0.05)$. In addition, there was no statistically significant difference between the mean scores of AVS according to age, residence, income status, education and profession status of the parents $(p>0.05)$ (Table 4$)$. There was
Table 1: Socio-demographic characteristics of students $(n=108)$.

Characteristics

Age; $20.13 \pm 1.17$ (min:18, max:26)

Gender

Female

Male

86

79.6

Age

20-24

$\geq 25$

85

Mother's education

Primary school

High-school

$\geq$ University

Father's education

Primary school

High-school

$\geq$ University

Mother's profession

Employed

Housewife

Father's profession

Employed

Retired

Residence

Urban

Rural

Income

Poor

Medium

High

Total

23

21.3

62.9

31.4

5.7

44.0

37.5

18.5

26.8

73.2

73.2

26.8

77.7

22.3

31.4

57.4

11.2

100.0

Table 2: AVS and subscales scores of students.

\begin{tabular}{|c|c|c|c|c|}
\hline AVS subscales & Min & Max & Mean & SD \\
\hline Economic & 7 & 35 & 26.15 & 5.31 \\
\hline Emotional-psychological-sexual & 6 & 25 & 18.24 & 4.32 \\
\hline Legitimizing myths & 3 & 20 & 12.16 & 3.01 \\
\hline Explanatory myths & 4 & 15 & 10.15 & 2.21 \\
\hline Total & 20 & 95 & 74.15 & 12.01 \\
\hline
\end{tabular}

Table 3: AORVS and subscales scores of students

\begin{tabular}{|c|c|c|c|c|}
\hline AORVS subscales & Min & Max & Mean & SD \\
\hline Supportive nursing interventions & 8 & 30 & 25.11 & 5.36 \\
\hline Continue the marriage under all conditions & 5 & 30 & 13.10 & 3.39 \\
\hline End the marriage union & 4 & 15 & 10.12 & 1.11 \\
\hline Negative view of the role of nurses & 3 & 15 & 11.23 & 2.84 \\
\hline Total & 20 & 90 & 65.24 & 9.30 \\
\hline
\end{tabular}

a statistical relationship between the mean scores of AORVS of the students and gender $(\mathrm{p}<0.05)$. While the mean AORVS score was $53.95 \pm 9.10$ for male students, it was determined as $60.12 \pm 9.40$ for female students. It was determined that there was no statistically significant difference between the mean scores of AORVS according to the age, residence, income, profession and education level of the parents of the students (p>0.05) (Table 5). 
Table 4: AVS scores of socio-demographic characteristics of students.

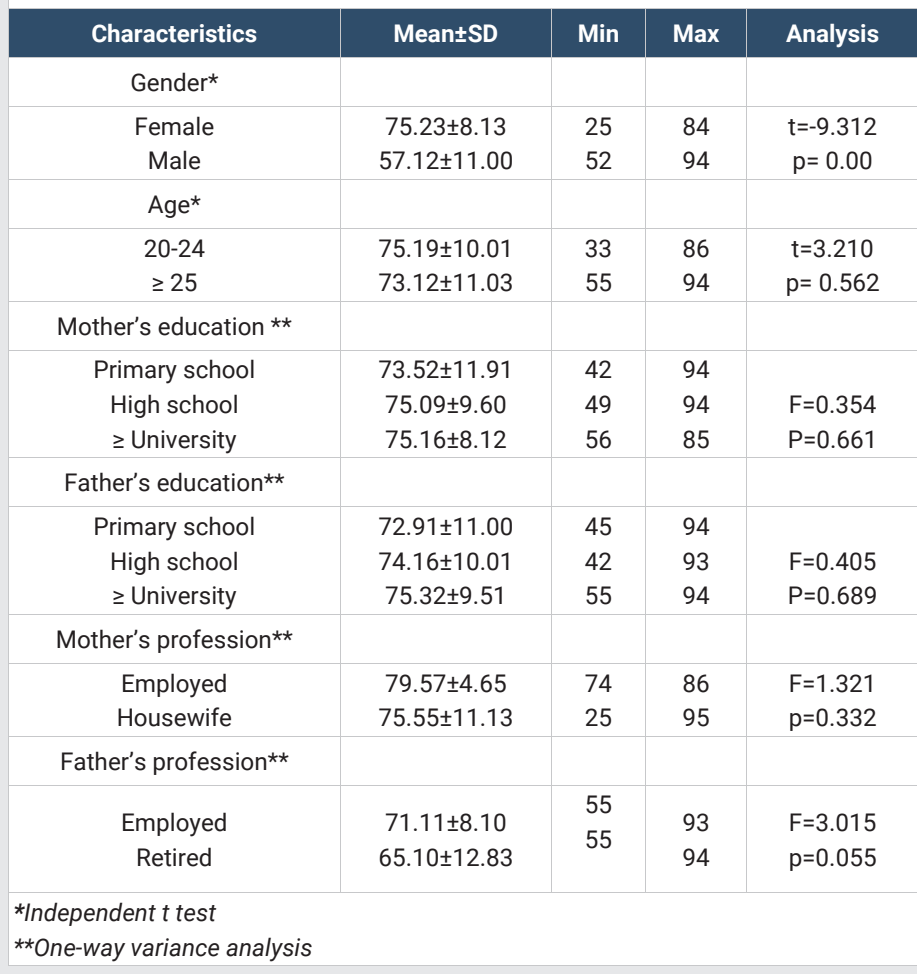

Table 5: AVORS scores of socio-demographic characteristics of students.

\begin{tabular}{|c|c|c|c|c|}
\hline Characteristics & MeantSD & Min & Max & Analysis \\
\hline \multicolumn{5}{|l|}{ Gender* } \\
\hline Female & $60.12 \pm 9.40$ & 44 & 75 & $t=-8.55$ \\
\hline Male & $53.95 \pm 9.10$ & 25 & 64 & $p=0.00$ \\
\hline \multicolumn{5}{|l|}{ Age $^{*}$} \\
\hline $20-24$ & $65.88 \pm 9.22$ & 40 & 78 & $t=2.910$ \\
\hline$\geq 25$ & $63.11 \pm 8.13$ & 44 & 74 & $p=0.211$ \\
\hline \multicolumn{5}{|c|}{ Mother's education** } \\
\hline Primary school & $60.00 \pm 7.07$ & 40 & 75 & $F=0.722$ \\
\hline$\geq$ University & $62.29 \pm 9.67$ & 44 & 70 & $p=0.781$ \\
\hline \multicolumn{5}{|c|}{ Father's education ${ }^{\star \star}$} \\
\hline Primary school & $59.48 \pm 7.32$ & 40 & 70 & $F=0.854$ \\
\hline$\geq$ University & $63.06 \pm 6.21$ & 45 & 75 & $p=0.125$ \\
\hline \multicolumn{5}{|c|}{ Mother's profession** } \\
\hline Employed & $64.43 \pm 7.97$ & 45 & 70 & $F=1.696$ \\
\hline Housewife & $60.44 \pm 7.51$ & 25 & 74 & $p=0.510$ \\
\hline \multicolumn{5}{|c|}{ Father's profession** } \\
\hline Employed & $60.71 \pm 8.60$ & 44 & 75 & $F=3.429$ \\
\hline Retired & $56.83 \pm 7.78$ & 40 & 70 & $p=0.060$ \\
\hline
\end{tabular}

*Independent $t$ test

**One-way variance analysis

\section{Discussion}

Nurses are in a key position in the provision of medical care, caregiving, advocating, supporting, and counseling services for individuals and their families. It is expected that nurses can establish a closer relationship with women who are experienced violence. Unfortunately, most women are not recognized due to nurses' unhelpful attitude towards VAW. Therefore, the physical and emotional signs of violence have not been completely identified among nurses despite education sessions.
Indeed, undergraduate nursing students' training is the most convenient period to promote appropriate knowledge, skills, and positive attitudes as well as their advocacy roles required to fight VAW $[2,5,7,14,15,18,20]$. In the present study, it is a remarkable finding that the majority of the students $(73.8 \%)$ stated that the subject of VAW should be comprehensively included in the curriculum. However, students did not have a contemporary view in reacting to violence (Table 2). In the studies conducted by Pinar \& Pinar [1], Bessette and Peterson [21], Doran \& Hutchinson [14], Bozkurt, et al. [17] and Kiyak \& Akın [22] the majority of the students and nurses reported a disapproving attitude about VAW. In addition, Karabulutlu (2015) [23], Sabancıgulları. et al. [24], Aktaş [25], and Yılmaz \& Öz [26] stated that the attitudes of nursing students towards VAW were more negative. These studies support our study results. The reason for this may be that violence is a learned behavior. Family views towards VAW can be influential on individuals' attitudes toward violence. In many societies, VAW is often justified as a private family matter. Many barriers to collaboration are based on these misperceptions $[9,18,26]$. Contrary to the findings of our study, some studies showed more positive attitude towards VAW than our results. In the studies of Hegarty [12], Pınar \& Sabuncuoglu [19], Yılmaz \& Yüksel [27] and Gombul [28], the attitudes of nurses' towards VAW seem to be in the direction of rejecting non-contemporary tendencies.

The present study demonstrated that students' attitudes towards their occupational supportive roles in violence also had a traditional tendency (Table 3). It is thought that the students still maintain their traditional attitudes due to their family structure. The cyclic nature of violence is emphasized by its transmission to generations to come, where accepting attitudes of gender inequalities still remain. In addition, the fact that the subject of violence against women in the Women's Health course consisted of only two hours in their curricula may have affected this result. In the study of Bozkurt, et al. [17], the majority of the students (95.2\%) stated that the health personnel was responsible for VAW, similarly, in the study of Tuncel, et al. [29], $68.9 \%$ of the students emphasized the importance of the role of the health workers in VAW. Other studies are parallel to our study; in the study of Sen, et al. [30], only $20 \%$ of nurses accepted the role of health workers in preventing violence. A study carried out on nursing students in Israel showed that they were not motivated to evaluate women in their practice for VAW, they were also limited information to recognize the sign of violence. In the same study, the authors stated that nurses support the scale statements stating that the nurse does not have time to spare for the woman who has been subjected to violence and that there is nothing the nurse can do about it [16]. In the study of Saeed. et al. [31] on the subject; it has been determined that health professionals have traditional attitudes regarding gendered role expectations that are culturally adapted and do not prevent violence against women. According to several studies, most health providers are still not routinely screening cases for VAW due to fear of offending patients, lack of appropriate training or confidence, lack of skills in responding to violence disclosures, lack of time for optimal care because of heavy workloads, lack of 
funding to improve new strategy, and lack of system-based scrutiny to identify victims of abuse $[15,17,32]$. In the light of previous literature, VAW is increasing dramatically in society and many cases of violence remain unnoticed within the health sector due to lack of awareness $[6,27,33]$ The mission of action plan to fight VAW around the world is to increase community awareness and to eliminate health providers' negative beliefs and attitudes towards VAW. This action plan also includes re-designed existing health education curricula and updating current programs due to shortage of content in the curriculum relevant to VAW at multiple levels. Specialized training strategies are required to reduce the gap between theory and practice [3]. Rodriguez. et al. [34] used innovative high-fidelity simulation models to improve nursing students' skills and knowledge on holistic nursing care such as active listening, counseling, problem solving, communication skill, anxiety control, empathy, and generating self-confidence towards VAW.

In the present study, it was determined that there was a statistically significant relationship between the AVS/AVORS score average and the gender of the students ( $\mathrm{p}<0.05)$, (Table 4). Female students were more traditional attitudes towards VAW. The high number of female students in our study may have an effect on this result. Also, this situation can be associated with being brought up in an environment where violence is supported, legitimizing violence or becoming desensitized to violence. Similarly, in the study of Sakallı-Ugurlu and Ulu [35], the men displayed more tolerant attitudes towards VAW. Contrary to our findings, Sabanciogulları, et al. [24], Doran \& Hutchinson [14], Ergüneri, et al. [36], Saeed-Ali, et al [31], Basar, et al. [20], Yılmaz \& Yüksel [28], and Rodriguez. et al. [34] found that men were more likely to have patriarchal attitudes towards VAW [37].

\section{Conclusions and recommendations}

As a result of this study, most of the students' attitudes towards VAW were traditional approaches, especially common among female students. They did not have a realistic view of their role in violence management. Therefore, the nursing curriculum should be designed to help the development of students' attitude, knowledge and skills required to respond in an appropriate manner by using effective learning strategies such as lectures, seminars, interactive simulation modalities, workshops, peer education, and role-play for students before starting professional life. Health educators should be strongly encouraged to find way further collaborative activities for nursing students to gain practical experiences of dealing with VAW. Also, qualitative in-depth studies should be performed to explore the causes of students' attitudes towards VAW.

\section{Limitation}

In this research, since there were no fourth-year students at the school, only third-year students were included. It is based on students' self-reports and a certain group of students was studied. We cannot generalize the views of the students in this study to all Turkish students.

\section{Acknowledgment}

The authors thank all students who participated in this study.

\section{References}

1. Tektaş P, Yildiz N, Kanbay Y, Işik E, Aslan Ö (2007) Üniversite Öğrencilerinde Kadına Yönelik Şiddetle İlgili Etmenlerin İncelenmesi. Artvin Çoruh Üniversitesi Uluslararası Sosyal Bilimler Dergisi 17: 76-83.

2. United Nation (2011) Handbook for National Action Plans on Violence against Women. Link: https://bit.ly/3GbhPol

3. World Health Organization (WHO) Violence against women Prevalence Estimates, 2018. Global, regional and national prevalence estimates for intimate partner violence against women and global and regional prevalence estimates for non-partner sexual violence against women. Geneva. Link: https://bit.ly/3f1k0iS

4. Yilmaz EB, Öz F (2019) Şiddete maruz kalan kadınlara yönelik güçlendirme programı ve hemşirelik. Head 16: 338-342. Link: https://bit.ly/3G64uy3

5. Miller E, McCaw B (2019) Intimate partner violence. New Eng J Med 380: 850857. Link: https://bit.ly/3qYsSv0

6. Sohal H, Feder G, Boomla K, Dowrick A, Hooper R, et al. (2020) Improving the healthcare response to domestic violence and abuse in UK primary care: Interrupted time series evaluation of a system-level training and support programme. BMC Med 18: 48. Link: https://bit.ly/3F3Gx95

7. Mancheno C, Aumaier B, Murray A (2020) Screening for intimate partner violence in a pediatric ED: A quality improvement initiative. Pediatr Emerg Care 37: e1110-e1115. Link: https://bit.ly/3HHO5Qz

8. Miller CJ, Adjognon O, Brady J, Dichter ME, Iverson KM, et al. (2021) Screening for intimate partner violence in healthcare settings: An implementation-oriented systematic review. Implement Res Pract 2. Link: https://bit.ly/3eVSIdE

9. Azad MS (2021) Experiences of Domestic Abuse within the South Asian Community. Journal of Global Faultlines 8: 50-68. Link: https://bit.ly/3t5izrC

10. Devine A, Spencer A, Eldridge S, Norman R, Feder G (2012) Cost-effectiveness of identification and referral to improve safety (IRIS), a domestic violence training and support program for primary care: a modelling study based on a randomised controlled trial. BMJ Open 2: e001008. Link: https://bit.ly/3G8va12

11. Wallin I, Eulau L, Bjarneby F, Westerborn M (2018) Women's experiences with healthcare professionals after suffering from gender-based violence: An interview study. J Clin Nurs 27: 949-957. Link: https://bit.ly/3n3gjO0

12. Hegarty K, McKibbin G, Hameed M, Koziol-McLain J, et al. (2020) Health practitioners' readiness to address domestic violence and abuse: A qualitative meta-synthesis. Plos One 15: e0234067. Link: https://bit.ly/3G3CN8N

13. Jeong Y, Lee K (2020) The development and effectiveness of a clinical training violence prevention program for nursing students. Int $\mathrm{J}$ Environ Res Public Health 17: 4004. Link: https://bit.ly/3HHreF0

14. Doran F, Hutchinson M (2016) Student nurses' knowledge and attitudes towards domestic violence: Results of survey highlight need for continued attention to undergraduate curriculum. J Clin Nurs 26: 2286-2296. Link: https://bit.ly/3G5tcP2

15. Renner LM, Wang Q, Logeais ME, Clark CJ (2019) Health Care Providers Readiness to Identify and Respond to Intimate Partner Violence. J Interpers Violence 36: 9507-9534. Link: https://bit.ly/3zHrpNO

16. Ben Natan $M$, Khater R, Igybariyea $H$, Herbet $H$ (2016) Readiness of nursing students to screen women for domestic violence. Nurse Educ Today 44: 98 102. Link: https://bit.ly/3eX2USX

Citation: Pinar G, Pınar E (2022) Attitudes of undergraduate nursing students towards violence against women and their occupational roles in addressing violence. Arch Nurs Pract Care 8(1): 001-006. DOI: https://dx.doi.org/10.17352/anpc.000058 
17. Bozkurt ÖD, Dasikan Z, Kavlak O, Sirin A (2013) Determination of the knowledge, opinions and professional attitudes of midwifery students about violence during pregnancy. Health Sci J 2: 99-107. Link: https://bit.ly/3368b8e

18. Çelik AS, Aydin A (2019) The effect of a course on violence against women on the attitudes of student midwives and nurses towards domestic violence against women, their occupational roles in addressing violence, and their abilities to recognize the signs of violence. Perspect Psychiatr Care 55: 210217. Link: https://bit.ly/3qVabZb

19. Gombul O (2000) Nurses attitudes towards violence imposed on women by her husband in the family and their professional role in violence. Nurs Res $\mathrm{J}$ 2: $19-32$.

20. Basar F, Demirci N, Çicek S, Saglam HY (2019) Attitudes Toward Violence Against Women and the Factors That Affect Them in Kutahya, Turkey. Afr J Reprod Health 23: 16-26. Link: https://bit.ly/3zwWSIA

21. Bessette HD, Peterson SS (2002) Attitudes of Adult Nurse Practitione Students toward Women Experiencing Domestic Violence. J Nurs Educ 41 27-30. Link: https://bit.ly/33a2ndQ

22. Kiyak S, Akin B (2010) Hemsire ve Ebelerin Kadina Yönelik Siiddet Konusunda Bilgi ve Tutumlar? Hemiirelikte Araitirma Geliitirme Dergisi 12: 5-16.

23. Karabulutlu $O$ (2015) Experiences and attitudes of nursing students regarding domestic violence against women. Cumhuriyet Nursing Journal 4: 24-34.

24. Sabancıogulları S, Yilmaz FT, Ar E, Cakmaktepe G (2016) The attitudes of nursing students towards violence against women and occupational role in violence, self-esteem and affecting factors. J Educat Res Nurs 13: 35-43. Link: https://bit.ly/3f1k5Dc

25. Aktas D (2016) Attitudes of university students towards domestic violence against women. Clin Invest Med 39: 27573. Link: https://bit.ly/3n4Rb9A

26. Okenwa-Emegwa L, Lawoko S, Jansson B (2016) Attitudes toward physical intimate partner violence against women in Nigeria. Sage Open 6: 1-10. Link: https://bit.ly/3F2rqNo

27. Pinar SE, Sabanciogullari S (2019) Nursing and Midwifery Students' Attitudes towards Violence against Women and Recognizing Signs of Violence against Women. Int J Care Sci 12: 1520-1529. Link: https://bit.ly/32WJbAC
28. Yilmaz EB, Yuksel A (2020) Factor affecting nursing students' attitudes towards violence against women: a cross sectional study. Cent Eur J Nurs and Midw 11: 85-93. Link: https://bit.ly/3F51WPo

29. Tuncel EK, Dündar C, Pesker Y (2007) Ebelik ve Hemirelik Öirencilerinin Aile içi iiddet Konusunda Bilgi ve Tutumlarinin Deierlendirilmesi 17: 105-110.

30. Sen S, Cetisli EN, Kavlak O, Sevil Ü (2012) Determination of awareness of health professionals about violence during pregnancy. 9: 20-33. Link: https://bit.ly/3qSVnKx

31. Saeed Ali T, Karmaliani R, Mcfarlane J, Khuwaja HMA, Somani Y, et al. (2017) Attitude towards gender roles and violence against women and girls (VAWG): baseline findings from an RCT of 1752 youths in Pakistan. Glob Health Action 10: 1342454. Link: https://bit.ly/3q2ex1v

32. Ali TS, Karmaliani R, Mcfarlane J, Khuwaja HMA, Somani Y, et al. (2017) Attitude towards gender roles and violence against women and girls (VAWG): Baseline findings from anRCT of 1752 youths in Pakistan. Global Health Action 10: 1342454. Link: https://bit.ly/3f1kfui

33. Pinar G, Taskin L, Eroglu K (2008) Baskent üniversitesi ö?renci yurdunda kalan gençlerin toplumsal cinsiyet rol kaliplarina iliskin tutumlari. Hacettepe Üniversitesi Saglik Bilimleri Fakültesi Hemsirelik Dergisi 15: 47-57. Link: https://bit.ly/34jRKpm

34. Rodriguez DJ, Belmonte García MT, Santillán García A, Plaza Del Pino FJ, Ponce-Valencia A, et al (2020) Nurse Training in Gender-Based Violence Using Simulated Nursing Video Consultations during the COVID-19 Pandemic: A Qualitative Study. Int J Environ Res Public Health 17: 8654. Link: https://bit.ly/3eYkWUX

35. Sakalli-Ugurlu N, Ulu S (2003) Attitudes towards violence against women in marriage: the effects of ambivalence sexism, age, education and income levels. Turkish Psychological Review 6: 53-65.

36. Er Guneri S (2016) Determination of university students attitudes towards violence againts women. Turkiye Klinikleri J Obstet Womens Health Dis NursSpecial Topics 2: 49-56.

37. Hewitt LN (2015) Intimate partner violence: The role of nurses in protection of patients. Crit Care Nurs Clin North Am 27: 271-275. Link: https://bit.ly/3q0tDEH
Discover a bigger Impact and Visibility of your article publication with

Peertechz Publications
Highlights

* Signatory publisher of ORCID

- Signatory Publisher of DORA (San Francisco Declaration on Research Assessment)

- Articles archived in worlds' renowned service providers such as Portico, CNKI, AGRIS, TDNet, Base (Bielefeld University Library), CrossRef, Scilit, J-Gate etc.

* Journals indexed in ICMJE, SHERPA/ROMEO, Google Scholar etc.

* OAI-PMH (Open Archives Initiative Protocol for Metadata Harvesting)

* Dedicated Editorial Board for every journa

* Accurate and rapid peer-review process

* Increased citations of published articles through promotions

* Reduced timeline for article publication

Submit your articles and experience a new surge in publication services (https://www.peertechz.com/submission).

Citation: Pinar G, Pınar E (2022) Attitudes of undergraduate nursing students towards violence against women and their occupational roles in addressing violence. Arch Nurs Pract Care 8(1): 001-006. DOI: https://dx.doi.org/10.17352/anpc.000058 